\title{
Parametric Study of different Levels of Detail of CityGML and Energy-ADE Information for Energy Performance Simulations
}

\author{
Avichal Malhotra ${ }^{1}$, Maksim Shamovich $^{1}$, Jérôme Frisch ${ }^{1}$, Christoph van Treeck ${ }^{1}$ \\ ${ }^{1}$ Institute of Energy Efficiency and Sustainable Building (E3D), \\ RWTH Aachen University, Germany
}

\begin{abstract}
Information handling and decision making for energy analysis at urban level is often difficult for simulation scientists. Often, a lack of the required Levels of Detail (LoD) of the information can be seen. Comparing the process of statistically enriching building archetypes for lower $\mathrm{LoD}$ to the usefulness of specific available information using the CityGML standard and Energy ADE for higher LoD, this paper will allow the users to make an efficient choice over the desired LoD for reducing the deviations in heating load simulations between monitored values and computed results.
\end{abstract}

\section{Introduction}

CityGML (Gröger et al. (2012)) represents an open Urban Information Modelling standard, based on a modular XML schema, is gaining popularity in many different applications (Biljecki et al. (2015)). In the domain of Building Performance Simulations (BPS), it can be a useful modelling language for dealing with large sets of information, for setting up urban level energy simulations and for further post-processing and visualizations. It is further extended by boundary representation methods, low computational cost, semantic and topological details and also appearance attributes.

The underlying concept of the Level of Detail (LoD) (Ridder et al. (2004)) of the CityGML standard allows multi-scale-representations of different city objects. Based on the complexity and resolution of geometric representations, the city objects are generalized by five discrete LoDs. Although the concept is applicable to most city objects representable by the CityGML standard, it is best suited for buildings. Apparently, the definition of multiple LoD for buildings is different from the coarseness of a building thermal zone. From a 2.5D Model (2D non-vertical polygon depicting the footprint, semantic information and a parameter for building height) in the LoD0 depiction, the LoD concept extends up to LoD4 for a 3D building model with an explicit roof shape, openings, outer installations and interiors (see Figure 1). A thorough discussion on CityGML LoD concept, its

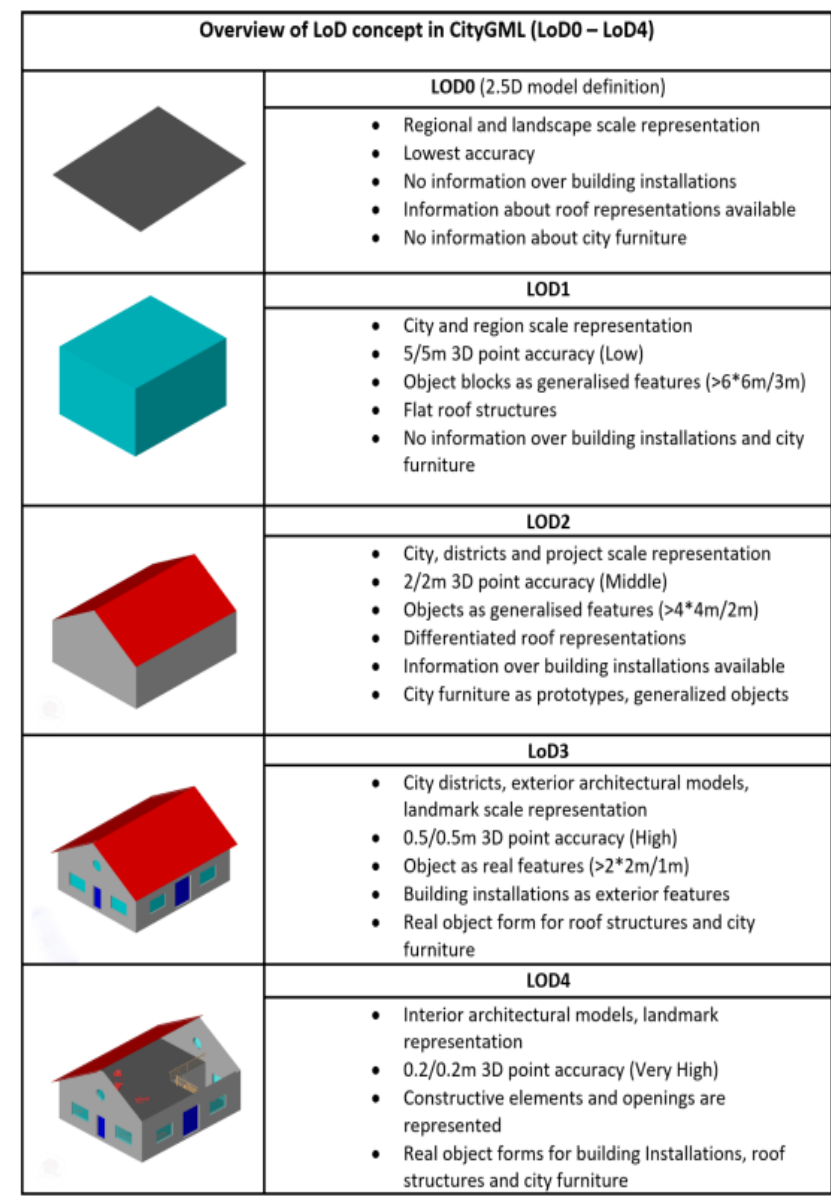

Figure 1: An example building considered for implemntation (FZK-Haus (2017)) in different Level of Detail (LoD). Information retrieved from (Gröger et al. (2012)).

limitations and possible improvements can be found in previous studies by Löwner et al. (2016) and Biljecki et al. (2016). Furthermore, for expanding the city objects with additional semantic information, relevant for energy analysis, CityGML offers generic attributes and an Energy Application Domain Extension (EnergyADE) (Agugiaro et al. (2018)). The modular structure of the EnergyADE is developed similar to the main standard and it can hold impor- 
tant information about building physics (thermal and usage zones description), materials and construction, occupant behaviour and energy systems.

Based on a quantitative analysis of the data required for energy simulations, this paper compares the approach of statistically enriching building archetypes using existing simulation platforms for data models with lower LoD to the one using more detailed available data in the CityGML Core module and Energy Application Domain Extension (ADE). Using free available CityGML sample files for different geographical locations (presently with an example building and in future with city wide dataset), a workflow highlighting the impact of different LoDs on building energy performance simulations at urban scale is further presented.

\section{Literature Background}

Emphasizing over different modelling techniques, extraction procedures and the enrichment algorithms, multiple studies are taken into consideration to determine the availability of software and frameworks adhering to CityGML standards.

Using open source LoD2 city models along with statistical census data, the Energy Atlas project (Krüger and Kolbe (2012)) assesses yearly and monthly energy demands of Berlin. Key indicators such as volume, reference area, envelope surface area, type, year of construction and usage of the building, based on correlations between building topology and its heating demands, are extracted and further used for simulations. Within the scope of this research, statistical enrichment (Kaden et al. (2013)) extends the computations to a physical steady-state algorithm based on "Energypass - heating/hot water" (Loga and Imkeller-Benjes (1997)). Through aggregations, demands for different buildings are computed and estimated. In another research, the CI-NERGY Project (Marie Curie Initial Training Network (2017)) developed software tools to facilitate urban decision making in sustainable energy related matters. CityGML data models (LoD0-LoD2) of Geneva and Vienna were used to serve as a web based source of harmonized information in the 3DCityDB (Yao et al. (2018)) tooled database (Agugiaro (2016)). Important parameters, based on ISO 13970 standard, for quasi-steady state heat demand calculation of residential buildings were identified. Moreover, shared walls, construction attributes and occupancy profiles for single thermal zones were considered (Skarbal et al. (2017)) .

Some approaches with dynamic simulation engines, such as EnergyPlus, are also generalized. In one such approach (Agugiaro et al. (2015)), enrichment methods were set to be identical to the non-dynamic simulations. An additional pre-processing was needed for the mapping of extracted attributes from the
CityGML source data to the EnergyPlus input format. The pre-processing was required due to the constrains EnergyPlus had in precision of the geometric prerequisites, modelling thermal zones and openings. Extensions for simulations were also implemented in the feature-set of the FZKViewer and GML-Toolbox by the Institute for Automation and Applied Computer Science, KIT (Hütter (2019)). The study by Geiger et al. (2018), presents the interface for thermal simulation engines (such as GebSim and EnergyPlus). Additional features to enhance the CityGML data with EnergyADE were also implemented. The models are also checked for geometric and semantic correctness, classifying walls between neighboring buildings and building parts. In the tool, enrichment of required thermal parameters can be carried out manually, with options to assign the construction layer by layer, or choose from pre-defined attributes. Usage profiles, used floor area and set point temperatures can also be defined in a similar way.

Furthermore, the urban energy simulation framework OpenIDEAS (Baetens et al. (2015)) is an open source research project by KU Leuven, allowing for multidisciplinary analyses in the field of district energy performance. One of the parts of this framework is a Modelica Library IDEAS (Baetens et al. (2012)). Using the TEASER tool (Remmen et al. (2016)) with the developed library, the effects of CityGML geometry on urban scale simulations is assessed. Within the scope of this study, firstly, the impact of important geometric data (ground floor area, heated floor area, heated volume, external wall area, window area, total loss surface area and internal wall area) over the peak power, total energy and overheating risk was analyzed (Jaeger et al. (2017)). In the follow up study (Jaeger et al. (2018)), six varying geometrical representations, from LoD1 (usual, only half of the roof height is considered, height depending on the building extension height), to LoD2 (reference model, aggregated surfaces into 4 cardinal and 8 half cardinal directions) are compared. In addition to the previous simulations set-up, two thermal zones are implemented, instead of a single one, for the whole building. The altered LoD1 models show indeed a lower deviation to the reference LoD2 model, but it is pointed out that the improvement is highly dependent on the observed building stock and the common roof types. The comparison of the simplified LoD2 representations show a significant decrease in computational time for both edited models, without a major loss in accuracy.

Moreover, the SimStadt platform (Eicker et al. (2016)) can perform an automated heating demand estimation on the basis of a monthly energy balance method (DIN V 18599). The workflow starts with CityGML models going through pre-processing, consisting of model checking and attribute extraction steps, in the CityDoctor (Wagner et al. (2013)) and (citygml4j (2018)) modules. The data is further en- 
riched with building physics information, load profiles and weather data and is further used to perform the thermal energy simulations using the INSEL simulation engine. Heating demand simulation results can be exported to the CityGML EnergyADE modular structure. Consistent with the proposed required attributes for thermal simulations depending on temporal resolution (Wate and Coors (2015)), the extracted information from the CityGML files include the geometry and semantic information about the usage and year of construction. This information is further used for the attribution to reference building physics information and occupant profile characteristics. This workflow was validated with districts in different German cities with actual consumption data (mainly gas demands for space heating) and indicated positive results (Eicker et al. (2012)). It was further tested in various scenarios with in depth investigations about the impact of heated attics (Nouvel et al. (2014)), the influence of information uncertainties like window-to-wall-ratio and usage profiles (Nouvel et al. (2013)), varying level of detail (from LoD1 to LoD3) (Strzalka et al. (2015)), deviations in the computed results comparing to a transient simulation engine (Monien et al. (2017)), and over the obstacles encountered in urban-scale energy modeling using CityGML and archetype method of data enrichment (Braun et al. (2018)).

The amount of required information for district energy performance simulations highly depends on the temporal resolution and targeted application area. Hence, the attributes extracted from CityGML sources vary as well. But it is usually kept to a minimum, to ensure the interoperability with the most prevalent CityGML data-sets, mainly LoD1 and LoD2. As a result of the previous studies, affiliated issues of missing data, inaccurate or incomplete information about building openings, shared walls, roof type and incorrect attribution of an archetype building, seem to have a higher effect on transient simulations. Many urban energy assessment platforms, therefore lay their focus on specific cities or districts, for which the amount of existing information is high, provided by administration or companies, and abstraining from dynamic simulations, which often require additional pre-processing or user input. The TEASER tool, in combination with the AixLib (Müller et al. (2016)), automates the simulation and enrichment operations. This framework offers dynamic simulations with detailed building models, acquired through CityGML and the implemented archetype enrichment process. The high temporal resolution and explicit modelling of the construction components not only allows for an accurate heat load prediction, but opens up more possible simulated alternatives in optimizing and refurbishment scenarios. With an increase in the demand for higher LoD of CityGML city models, computing power and sophisti- cation of urban dynamic energy simulation platforms, it is important to investigate upon the relevance of different LoDs for energy simulations.

\section{Methodology}

Comparing to the building engineering and energy performance analysis carried out in the 19th century (Kusuda (2017)) (Lau and Ayres (1979)), the concept of LoD in GIS for urban level energy performance simulation gives significantly higher degree of freedom in order to enhance the simulation models with much high level of accuracy comparing to the real world. To highlight the impact of the various LoDs on dynamic energy simulations, the Tool for Energy Analysis and Simulation for Efficient Retrofit (TEASER), using the version 0.5.2 of AixLib, was extended to process LoD0, LoD3, LoD4 and different LoDs (LoD0-LoD3) along with the EnergyADE input data. Using an archetype approach, TEASER, categorizes different buildings based on certain basic parameters such as usage, year of construction and enveloped volume. The number of elements, which describes the order of segregation of the different surfaces according to their inclination, was set to 4 in TEASER. Using the tool, individual building models are created which are further enriched with essential details over the construction type and materials, boundary conditions and the occupancy loads. TABULA, (Loga et al. (2015)) for residential and non-residential building constructions of the German building stock, is one such example of the sources TEASER uses for the statistical enrichment. AixLib, an open source Modelica library, facilitates thermodynamic behavioural simulations of buildings, HVAC systems and distribution networks. As part of the Annex 60 project (Wetter et al. (2015)), AixLib was one of four libraries which enables energy system analysis both for single buildings and urban scale. AixLib facilitates the modelling process of different buildings both as higher and lower order models. For the lower order models created using AixLib, adiabatic outer walls are represented by two thermal resistances and one capacitor, while the inner walls are modeled with one resistance and one capacitor. Additional influence on the dynamic energy behaviour by some internal loads including occupants, heating, lighting and other machinery (as heat sources) and ventilation (as a heat sink) can be observed. The effects of solar radiations are handled separately for outer wall surfaces and windows with the help of the average equal air temperatures.

The previously implemented import and enrichment functionalities, of the geometric and semantic information, for LoD1-LoD2 CityGML building models in TEASER were used as the basis of the futher extensions. LoD0 models can be parameterized as long as the CityGML file has semantic information regarding the building height or amount of storeys. For the 
building models in LoD3, the extraction and enrichment of opening surfaces was developed. Similarly, construction and material attributes were derived from already existing datasets in TEASER. Whereas, for building in LoD4 the interior wall surfaces were calculated, rather than using the estimated value provided by TEASER, still using the same construction type. Using the EnergyADE v1.0, data relevant for the energy analysis, such as construction materials and occupant, lighting and machinery attributes, was mapped to the building models. Since the extensions were developed using the existing datasets of TEASER, few manipulations and additions had to be implemented in the TEASER XML bindings. In the present functionality, materials and load profiles, which might not be in the previous versions of TEASER, were also introduced.

\section{Results}

CityGML data models for LoD, higher than LoD2, are comparatively less openly available. Therefore, an example building, namely, the FZK House (Figure 1, EnergyADE (2018)), was used as a prototype to test the developed approach. This example model provides different LoD representations (LoD0-4) of the same structure, including a LoD2 connected with the EnergyADE. According to the propositions made in (Clarke (2015)), standard simulation models and open-source monitoring data would be neccessary to compare the simulation results with the real time consumptions.

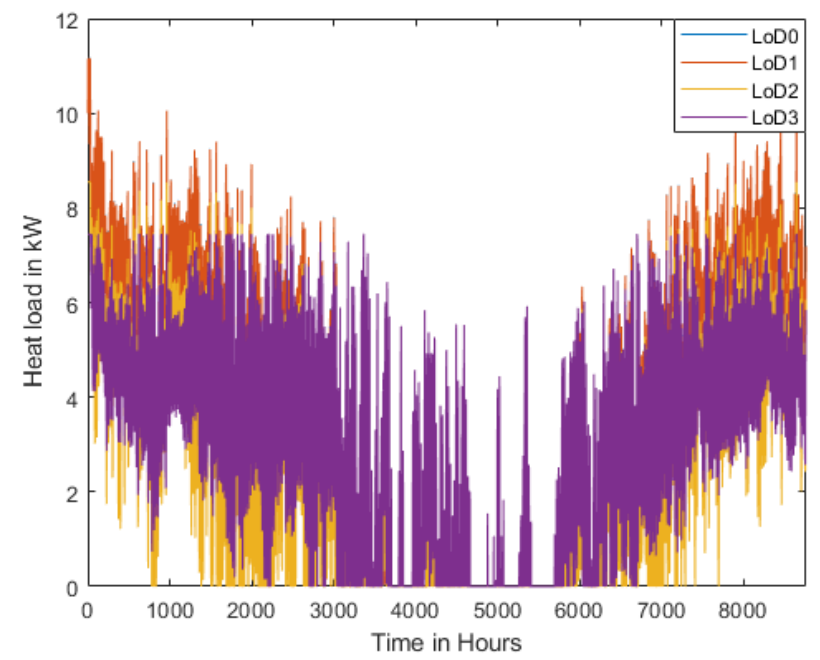

Figure 2: Hourly heating loads simulation results for LoD0, LoD1, LoD2 and LoD3 for the year 2010 using a toolchain containing TEASER, AixLib and Dymola.

To enable a realistic enrichment of the data models, without the EnegyADE, the example buildings were characterized as residential buildings, using the "single family dwelling" archetype model of TEASER as the starting foundation and the construction year was set to 2010. The default value of the window per fa- cade ratio was taken as $20 \%$ of the associated wall surface. Two "number of stories" were defined with half of the building's "measured height". Due to the non availability of zone definition for core CityGML attributes and the scarcity of zonal information available as open source, the whole building is considered as a single thermal zone. However, multiple thermal zone definition for residential and non residential buildings and an investigation over the computational times for multiple zones will be a part of the future work. At present, efforts to gather topological data for characterising building thermal zones from sources such as Institut Wohnen und Umwelt (IWU) and TABULA for urban scale simulations are being made. Weather data from the Test Reference Year (TRY) for the closely located city of Manheim for the year 2010 was used for the simulations. Furthermore, in case of LoD2+EnergyADE data model, no additional data besides the weather data from TEASER was used. With the goal to compare the deviations in the computed heating demands for the whole year, the LoD2 model was chosen as reference, as this represents the most detailed model widely available for the German building stock.

In the following graphs, a comparision regarding the heating demand results, between the different LoDs for CityGML data is presented.

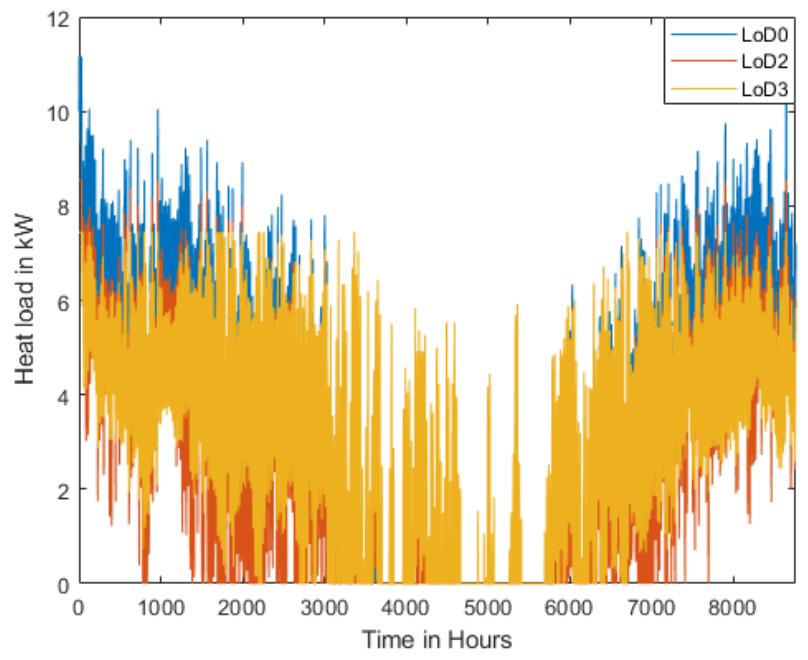

Figure 3: Hourly heating loads simulation results for LoD0, LoD2 (reference) and LoD3 for the year 2010.

In the Figure 2, the deviations in the computed results for the LoD0 model and the LoD1 model are very small. Nevertheless, some deviations that could be seen in the figure are mainly due to the use of the roof edge, in the LoD0 CityGML model, as ground slope. Furthermore, the less precise geometry of the LoD1 model, compared to the reference LoD2 building, results in an overestimated heating load. The LoD1 model possesses a 13\% larger surface area and a $26 \%$ higher attributed window area. The differences mainly stem from the explicit roof model. The 
estimations are constantly above the reference plot, showing the same dynamic behaviour in the seasonal trends and periodic movement.

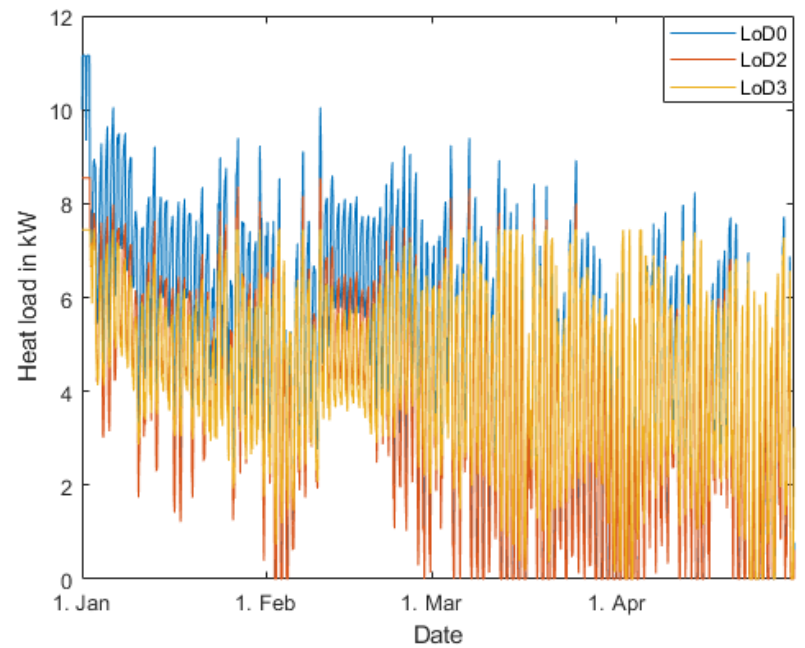

Figure 4: Hourly heating loads simulation results for LoD0, LoD2 (reference) and LoD3 for January to May in 2010.

Another analysis for LoD0, LoD2 and LoD3 is made in Figure 3. Here, the explicit window representation in the LoD3 model, reveal a nearly $50 \%$ overestimation of the window area, during the parameterisation. Even with the modest assumption of $20 \%$ for the window-to-wall-ratio, the LoD3 based simulated heat load is mostly lower compared to the reference LoD2, though the simulated LoD3 model displays more heating hours in total. Figure 4 and Figure 5 highlight the deviations as the results are analyzed on a resolution of 5 months (January to May) in winters and on a resolution of one week in February.

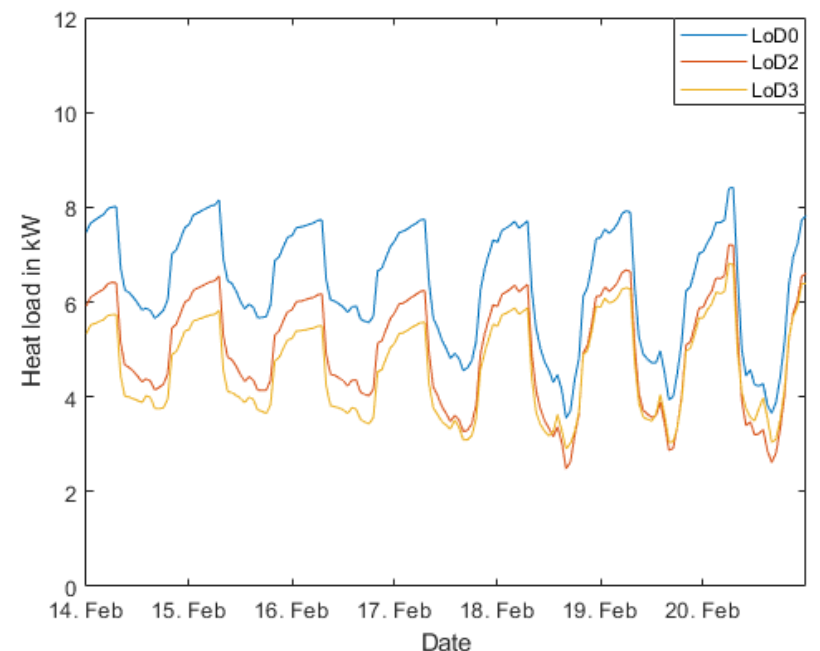

Figure 5: Hourly heating loads simulation results for LoD0, LoD2 (reference) and LoD3 for 14th and 21st February in 2010.

Furthermore, when comparing the computed heating demand estimation results for the LoD2 data model with and without EnergyADE (Figure 6), (Figure 7) and (Figure 8), deviations can also be seen.

Since the LoD2+EnergyADE data model do not have any interior walls modelled, it does have the smallest heated volume as well. Moreover, as the EnergyADE data is attached to extend the LoD2 building, the recorded thermal opening area deviates from the explicit representation and is the highest in comparison. The heating load curves show the least oscillations during the daily temperature cycle. Consequently, causing the highest deviation value to the LoD2 model in the final comparison.

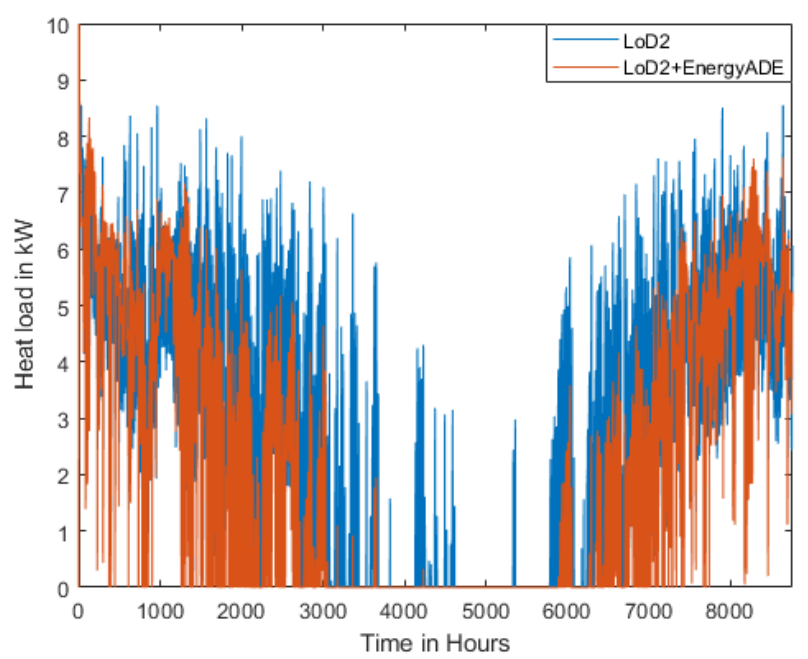

Figure 6: Hourly heating loads simulation results for LoD2 (reference) and LoD2+EnergyADE data for the year in 2010.

Though simulations with detailed models will result in less deviations to the real time data, in Figure 9, an overall analysis between the different LoDs for the considered CityGML model, based on the mean heating loads, peak heating loads and the maximum deviation from the reference LoD2, based on its availability, is made. For the simulated heating demand estimations in 2010, the LoD2 model has the smallest mean heating load for a year. Whereas, the LoD3 model had the smallest peak heating load. Since the building volume calculation in TEASER does not take the roof surface into account, but rather the buildings ground slope and measured height. Hence, the volume for the building in the different LoDs was considered to be the same. For the LoD2+EnergyADE model, the included gross volume, $22 \%$ smaller than the estimated one due to the consideration of the explicit roof structure, was used for calculations. The inner wall area was overestimated by nearly $80 \%$ compared to the LoD4 inner layout model, which the authors would like to consider in the future works.

The pre-processing and simulation time of all LoDs were quite similar and stayed in the single second range. Only the pre-processing time of the LoD4 


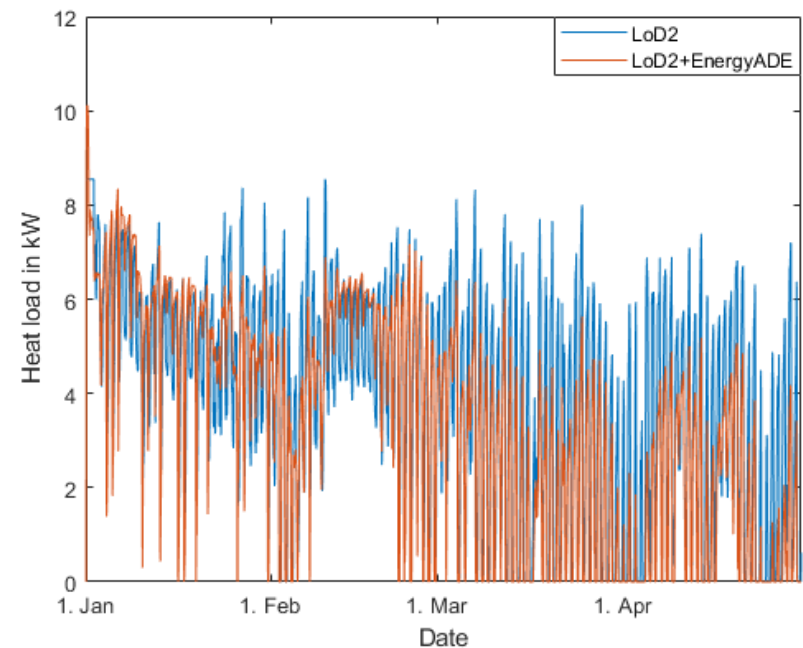

Figure 7: Hourly heating loads simulation results for LoD2 (reference) and LoD2+EnergyADE data for January to May in 2010.

model was notably longer, due to the significantly larger file size. However, the simulation time was not effected by the more complex model.

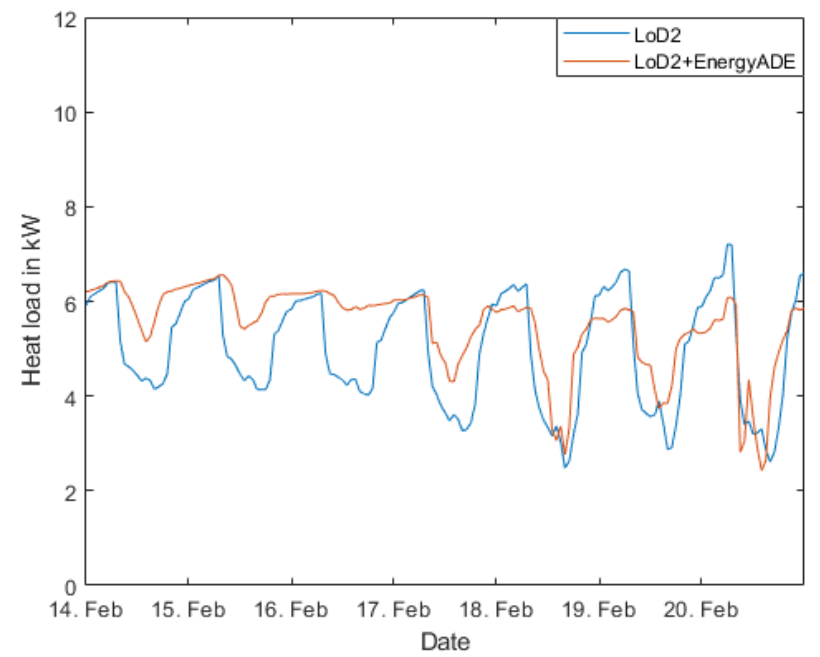

Figure 8: Hourly heating loads simulation results for LoD2 (reference) and LoD2+EnergyADE data for 14 th to 21st February in 2010.

\section{Conclusion and Future Work}

The deviations between the various LoDs for CityGML data models will increase with the correct volume calculations. Since CityGML data models in LoD2 and LoD1 only are prominently available as open source, the simulation results highly depend on the statistical data used for further enrichment. The current implementation of TEASER is more suitable for flat roof types, and multi-storey or large ground floor buildings, in which the heated volume is considerably less affected by the simplified computations. The inner wall calculations in TEASER are as well, more suitable for multi-storey buildings, which affect solely the overall heat storage capacity, but plays a vital part in the heating load simulations. With the flexibility of extending the internal building topological libraries, construction material data, occupancy profiles, etc for enriching the parameters, the developed extension to TEASER will allow the user to independly use the tool for different geographical loactions and building types. Comparing to simulation environments such as EnergyPlus, IES-VE (Integrated Environmental Solutions - Virtual Environment) and TRNSYS (Drury et al. (2005)), the implemented extension for TEASER (TEASER+, to be available soon as open source) will be much more user friendly and could be used by the experts of multiple domains. In this paper, a comparison between the deviations in the simulation results based on the availability and granularity of the data models is presented. Moreover, considering the simulation results for a single building, the deviations in heating load demands using different LoD for a large urban scale can be estimated in a coarse way. However, a detailed analysis could be made using realistic enrichment data depending upon the level of detail of the building models.

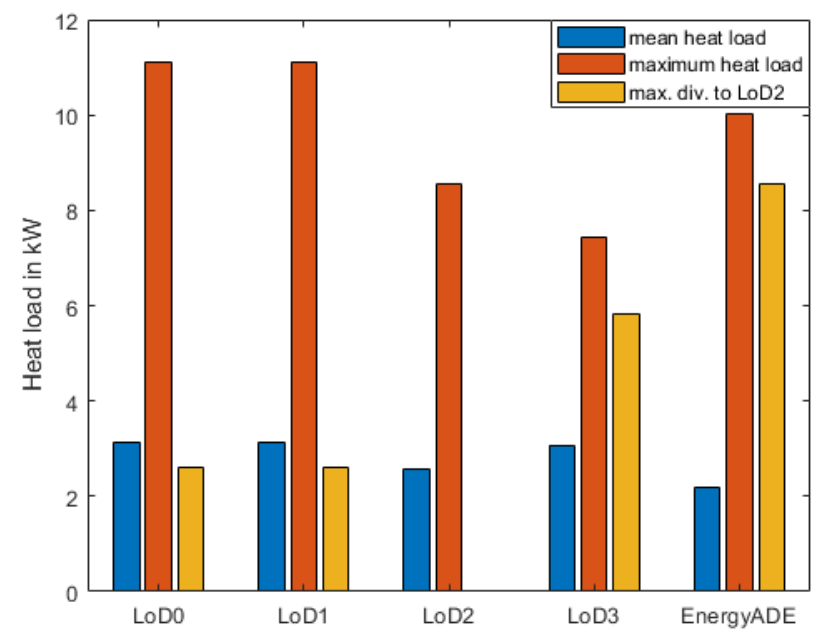

Figure 9: Mean heating loads, peak heating loads and maximum deviation to the reference LoD2 in kiloWatts for a test reference year 2010.

A further investigation over the computational time and the enrichment process of the LoD4 CityGML data model will be carried out by the authors. Simulations based on multiple thermal zone definitions of the buildings will be carried out in the next steps. Furthermore, a sensitivity analysis for the attributes within the different LoDs will also be a part of the future studies for the authors. With open LoD1 and LoD2 data for multiple cities, the authors would also like to extend the tool chain for district and urban simulations. 


\section{Acknowlegement}

We gratefully acknowledge the financial support by BMWi (German Federal Ministry of Economic Affairs and Energy), promotional reference 03ET1410B.

\section{References}

Agugiaro, G. (2016). Enabling Energy-Awareness in the semantic 3D City Model of Vienna. ISPRS Annals of Photogrammetry, Remote Sensing and Spatial Information Sciences $I V-4 / W 1,81-88$.

Agugiaro, G., J. Benner, P. Cipriano, and R. Nouvel (2018). The Energy Application Domain Extension for CityGML: Enhancing interoperability for urban energy simulations. Open Geospatial Data, Software and Standards 3(1), 139.

Agugiaro, G., S. Hauer, and F. Nadler (2015). Coupling of CityGML-based Semantic City Models with Energy Simulation Tools: Some Experiences. Proceedings of the 20th International Conference on Urban Planning.

Baetens, R., R. Coninck, J. van Roy, B. Verbruggen, J. Driesen, L. Helsen, and D. Saelens (2012). Assessing electrical bottlenecks at feeder level for residential net zero-energy buildings by integrated system simulation. Applied Energy 96, 74-83.

Baetens, R., R. Cornick, F. Jorissen, D. Picard, L. Helsen, and D. Saelens (2015). OPENIDEAS: An open Framework for interated District Energy Simulations. In Proceedins of BS2015.

Biljecki, F., H. Ledoux, J. Stoter, and G. Vosselman (2016). The variants of an LOD of a 3D building model and their influence on spatial analyses. ISPRS Journal of Photogrammetry and Remote Sensing 116, 42-54.

Biljecki, F., J. Stoter, H. Ledoux, S. Zlatanova, and A. Çöltekin (2015). Applications of 3D City Models: State of the Art Review. ISPRS International Journal of Geo-Information 4 (4), 2842-2889.

Braun, R., V. Weiler, M. Zirak, L. Dobisch, V. Coors, and U. Eicker (2018). Using 3D CityGML models for building simulation applications at disctrict level: Improvements in simulation workflow to achieve a better fit between simulated and measured data. In ICE/IEEE (Ed), Proceedings of ITMC 2018 .

citygml4j (2018). The Open Source Java API for CityGML.

Clarke, J. (2015). A vision for building performance simulation: a position paper prepared on behalf of the ibpsa board. Journal of Building Performance Simulation, 8(2), 39-43.
Drury, C., J. Hand, M. Kummert, and B. Griffith (2005). Contrasting the capabilities of building energy simulation software tools.

Eicker, U., V. Coors, R. Nouvel, K.-H. Brassel, E. Duminil, and M. Bruse (2016). SimStadt: Energiesimulation von Stadtquartieren. Schlussbericht, Hannover, TIB-Technische Informationsbibliothek Universitätsbibliothek and Informationsbibliothek, Technische and Hochschule für Technik Stuttgart, Institut für Angewandte Forschung and Hochschule für Technik Stuttgart, Zentrum für Nachhaltige Energietechnik.

Eicker, U., R. Nouvel, C. Schulte, S. J, and V. Coors (2012). 3D-Stadtmodelle für die Wärmebedarfberechnung. In IBPSA (Ed), Proceedings of BauSIM 2012.

EnergyADE, F. (29.06.2018). KIT Sample files Energy ADE, Karlsruhe Institute of Technology (KIT) Institute for Applied Computer Science CityGML Example FZK-House.

FZK-Haus (19.07.2017). KIT Sample files, Karlsruhe Institute of Technology (KIT) Institute for Applied Computer Science (Campus North) CityGML Example FZK-Haus.

Geiger, A., J. Benner, K.-H. Häfele, and V. Hagenmeyer (2018). Thermal Energy Simulation of Buildings based on the CityGML Energy Application Domain Extension. In Proceedings from BauSIM2018 - 7. Deutsch-Österreichische IBPSAKonferenz, Karlruhe. KIT.

Gröger, G., T. H. Kolbe, C. Nagel, and K. H. Häfele (2012). OGC City Geography Markup Language (CityGML) Encoding Standard.

Hütter, J. (07.01.2019). KIT - IAI Homepage: Download.

Jaeger, I., G. Reynders, Y. Ma, and D. Saelens (2018). Impact of building geometry description within district energy simulations. Energy 158, 1060-1069.

Jaeger, I., G. Reynders, and D. Saelens (2017). Impact of spatial accuracy on district energy simulations. Energy Procedia 132, 561-566.

Kaden, R., M. Prytula, A. Krüger, and T. H. Kolbe (2013). Energieatlas Berlin: Vom Gebäude zur Stadt: Am Beispiel zur Abschätzung der Wärmeenergiebedarfe von Gebäuden. Geoinformationssysteme 2013 - Beiträge zum 18. Münchner Fortbildungsseminar Geoinformationssysteme.

Krüger, A. and T. H. Kolbe (2012). Building Analysis for Urban Energy Planning using Key Indicators on Virtual 3D City Models: The Energy Atlas Berlin. ISPRS - International Archives of the 
Photogrammetry, Remote Sensing and Spatial Information Sciences XXXIX-B2, 145-150.

Kusuda, T. (2017). Early history and future prospects of building performance simulations.

Lau, H. and J. Ayres (1979). Building energy analysis programs.

Loga, T. and U. Imkeller-Benjes (1997). Energiepaß Heizung/Warmwasser - Energetische Qualität von Baukörper und Heizungssystem.

Loga, T., B. Stein, N. Diefenbach, and R. Born (2015). Deutsche Wohngebäudetypologie (2., erw. Aufl. ed.). Darmstadt: IWU.

Löwner, M.-O., G. Gröger, J. Benner, F. Biljecki, and C. Nagel (2016). Proposal for a new LoD and multirepresentation concept for CityGML. ISPRS Annals of Photogrammetry, Remote Sensing and Spatial Information Sciences $I V-2 / W 1,3-12$.

Marie Curie Initial Training Network (09.03.2017). CINERGY: a FP7 European Project.

Monien, D., A. Strzalka, A. Koukofikis, V. Coors, and U. Eicker (2017). Comparison of building modelling assumptions and methods for urban scale heat demand forecasting. Future Cities and Environment 3(0), 2.

Müller, D., M. Lauster, A. Constantin, M. Fuchs, and P. Remmen (2016). AixLib - An Open-Source Modelica Library within the IEA-EBC Annex 60 Framework. In Proceedings of the CESBP Central European Symposium on Building Physics and BauSIM 2016 : September 14-16, 2016, Dresden, Germany.

Nouvel, R., C. Schulte, U. Eicker, D. Pietruschka, and V. Coors (2013). CityGML-based 3D City Model for Energy Dianostics and Urban Energy Policy Support. In IBPSA (Ed), Proceedings of BS2013.

Nouvel, R., M. Zirak, H. Dastageeri, V. Coors, and U. Eicker (2014). Urban Energy Analysis based on 3D City Model for national scale applications. In Proceedings of BauSIM2014, 5th German-Austrian IBPSA Conference, Aachen 2014.

Remmen, P., M. Lauster, M. Mans, M. Fuchs, T. Osterhage, and D. Müller (2016). TEASER: An open tool for urban energy modelling of building stocks. Journal of Building Performance Simulation 11(1), 84-98.

Ridder, I., K. Nellessen, J. Albert, J. Schubert, C. Buddendick, U. Hannok, U. Herting, B. Petzold, and H. Wanzke (2004). Eine orientierungshilfe für die städte in nrw.
Skarbal, B., J. Peters-Anders, A. Faizan Malik, and G. Agugiaro (2017). How to pinpoint EnergyInefficient Buildings? An Approach based on the 3D City Model of Vienna. ISPRS Annals of Photogrammetry, Remote Sensing and Spatial Information Sciences IV-4/W3, 71-78.

Strzalka, A., D. Monien, A. Koukofikis, and U. Eicker (2015). Sensitivity analysis for minimization of input data for urban scale heat demand forecasting. In WSSET (Ed), Proceedings of SET2015.

Wagner, D., N. Alam, and V. Coors (2013). Geometric validation of $3 \mathrm{D}$ city models based on standarized quality criteria. In Urban and Regional Data Management, UDMS Annual 2013 - Proceedings of the Urban Data Management Society Symposium 2013, pp. 197-210.

Wate, P. and V. Coors (2015). 3D Data Models for Urban Energy Simulation. Energy Procedia 78, 3372-3377.

Wetter, M., M. Fuchs, P. Grozman, L. Helsen, F. Jorissen, M. Lauster, D. Muller, C. NytschGeusen, Picard D., P. Sahlin, and M. Thorade (2015). IEA EBC Annex 60 Modelica library: An International colaboration to develop a free opensource model library for building and community energy systems: 14th Conference of International Building Performance Simulation Association, Hyderabad, India, Dec. 7-9, 2015. Proceedings of BS2015.

Yao, Z., C. Nagel, F. K., G. Hudra, P. Willkomm, A. Donaubauer, T. Adolphi, and T. H. Kolbe (2018). 3DCityDB - a 3D geodatabase solution for the management, analysis, and visualization of semantic 3D city models based on CityGML. Open Geospatial Data, Software and Standards 3(1), 208. 